\title{
Emmanuel Dias and Trypanosoma cruzi discovery: two centenaries to celebrate - Editorial
}

When Carlos Chagas was discovering the parasite Trypanosoma (Schizotrypanum) cruzi in 1908, one of the more important researchers on Chagas disease, Emmanuel Dias, was borning.

Emmanuel Dias was born in Rio de Janeiro, Brazil. He was the son of Ezequiel Caetano Dias, a distinguished colleague of Carlos Chagas, and Maria Cândida Fonseca Dias. Ezequiel Dias was another brilliant scientist, who worked with his brother-in-law Oswaldo Gonçalves Cruz from the opening of Instituto Oswaldo Cruz, the pioneering experimental medicine institution in Latin America that had been founded in the early 1900's in Manguinhos, Rio de Janeiro.

At that time, Carlos Chagas was also working in Manguinhos, and was involved with malaria research and control. In 1907, Oswaldo Cruz placed Chagas in charge of malaria control in the Lassance region, in the state of Minas Gerais, where this parasitic disease was causing major difficulties for the construction of the Central do Brasil Railway. Following the tradition of his Institute, in parallel with his main work, Chagas also studied the fauna of Lassance, and discovered a new trypanosome (T. minasense), in 1908, that was parasitizing the black tufted marmoset Happale penicillata $(=$ Callithrix penicillata). Around the same time, Chagas discovered another flagellate, that he named Schizotrypanum cruzi (= Trypanosoma cruzi) in the gut of a hematophagous bug of the region, the Conorrhinus megistus (= Panstrongylus megistus). Some months later, after hard laboratory labor concerning the life cycles of T. cruzi in the vector and small mammals in Manguinhos, Chagas returned to Lassance and found his first human case of a new disease, which was later called "Chagas disease" by Miguel Couto, the President of the Brazilian Academy of Medicine.

Emmanuel Dias lost his father at the age of 14, a fact that strongly reinforced his determination to follow Ezequiel Dias' career. In Rio de Janeiro, Emmanuel Dias began his Medicine Course in 1927, at the same National Medicine School where Ezequiel Dias, Carlos Chagas, and Oswaldo Cruz had also studied some decades before. During the second year at the University, Emmanuel Dias started a voluntary fellowship with his godfather, Carlos Chagas, at Instituto Oswaldo Cruz, where he was advised to study the biology of $T$. cruzi in its invertebrate and vertebrate hosts. Emmanuel Dias very quickly became one of the most important Chagas disciples and never forgot one of his Mentor's major obsessions: "It is absolutely mandatory to put an end with this lamentable disease!" His 1932 thesis, entitled "Studies about the Schizotrypanum cruzi", is still considered to be a salient scientific reference today. He published this monograph in 1934 at Memórias do Instituto Oswaldo Cruz (Dias E 1932. Estudos sobre o Schizotrypanum cruzi. Mem Inst Owaldo Cruz 28: 1-110; available from: http://memorias.ioc.fiocruz.br/pdf/Tomo28/ tomo28(f1)_1-110.pdf), and nearly $20 \%$ of his contributions to science were published at this journal.

Chagas died in 1934, and Emannuel Dias replaced him at the laboratory, dedicating his time solely to T. cruzi studies (biometry, bats trypanosomes, xenodiagnosis, T. rangeli, among other subjects). In 1935, E Dias met Cecilio Romaña and Salvador Mazza in Argentina and brought information back to Brazil about the acute Chagas disease, particularly about the "Romaña's sign", a very typical clinical picture of the acute phase. As a consequence of Romaña's description, several acute cases were rapidly detected in Argentina, Uruguay, and other countries. In Brazil, an important focus in Bambuí, in the state of Minas Gerais, was discovered by Amilcar Vianna Martins, in 1940. In 1943, the Director of Instituto Oswaldo Cruz, Henrique de Beaurepaire Aragão, chose E Dias to establish an advanced center for the study and prevention of Chagas disease in the small county of Bambuí. E Dias remained in Bambuí for twenty years, until his death in 1962.

The transformation of the brilliant protozoologist E Dias during his stay in Bambuí was absolutely radical. Therefore, E Dias immediately became convinced that the main impact of human disease was that it is a social tragedy involving thousands or millions of rural and poor citizens in Latin America. Through his intense study of the harsh epidemiological reality he found in Bambuí, E Dias concluded that three main rational points would guide his approach to Chagas disease: (i) the basic mechanism of transmission was a consequence of indoor concentration of the vector that is the main target for disease prevention, (ii) the basic social impact of the disease remained in its chronic cardiopathy, a medical entity not well recognized at that time, and (iii) the fight against Chagas disease would depend on political will and continuous prophylactic actions from different protagonists.

From that time on, E Dias made simultaneous and vigorous progress on these three points, involving several scientists, health authorities, communication professionals, and politicians. Beginning from Bambuí, he developed all the basic issues against the domestic triatomines, from housing improvements to modern insecticides and health education. In 1947, E Dias, along with his assistant José Pellegrino, described the strong and residual action of the "Gammexane" insecticide against triatomines, and convinced his friend Mario Pinotti (head of the National Department of Rural Endemics) to perform a large field trial in the states of Minas Gerais and São Paulo. Some time later, E Dias proposed the same procedures in Chile, Uruguay, Venezuela, and Argentina. In the middle of the 1950s, he developed the whole strategy for Triatoma infestans (the most dangerous vector species in the Southern Cone) elimination and reached this desideratum in Bambuí and other neighborhoods. At the same time, E Dias was developing his other targets. Along with Francisco Laranja, Genard Nóbrega, and other partners, the chronic phase of the 
disease was completely reviewed in more than 7,000 patients, particularly the chronic Chagas heart disease, which was totally systematized. Their publication "Chagas' disease: a clinical, epidemiological, and pathologic study" (Circulation 14: 1035-1060; 1956) is considered one of the most important papers regarding chagasic cardiopathy in all the history of Chagas disease. In parallel, Dias and his group became the pioneers in clinical and serological studies in endemic areas. Fred Soper, from PAHO, told him once that it was not sufficient to conduct good investigations or even to find good solutions; rather it was necessary "to sell the idea". Combining good serology with electrocardiographical studies in the general population, E Dias and colleagues showed the medical impact of the disease in large portions of Latin America. Furthermore, E Dias went directly to the politicians and different opinion makers of the time, showing them the tragedy of the disease and the stark realities that they had to face.

E Dias died in 1962 at the age of 54, due to an automobile accident, amidst a fervent effort to implement a national fight against Chagas disease in Brazil. At the end of this decade, the state of São Paulo put in course its successful local program. Ten years later, actions against the vector were systematized all over the country, becoming a nation priority in 1983. In 1991, the Southern Cone Initiative was launched with assistance from PAHO followed some years later by similar "Initiatives" in Andean, Central America, and Amazon Countries. In 2006, Brazil was declared free of vector transmission by $T$. infestans, preceded by Uruguay and Chile. The number of acute cases has decreased drastically in the last two decades in Brazil, as has the mortality and the morbidity due to T. cruzi infection. At the same time, millions of young Latin American individuals have been protected from the dangers of parasite contamination. At the heart of these achievements lie the life and labor of Emmanuel Dias.

In 2008, the scientific community involved with Chagas disease is celebrating the centenary of this scientist, who would one day assume the obsession of his Mentor, which entirely changed his life, and made the major dream of Chagas a reality. For this commemoration, from a pragmatic and more consequent point of view, the best action is to pursue the consolidation of Chagas disease control in all endemic areas. There is a severe risk associated with weakening the necessary surveillance against secondary and peridomestic vectors. In parallel, millions of infected individuals continue to require better and more adequate medical care. Governments, scientists, and health authorities must remain active and responsible for facing the present challenges of Chagas disease. Such an attitude is required to definitively eliminate the tragedy associated with American Trypanosomiasis, which will also contribute to keeping the aspirations of Carlos Chagas and Emmanuel Dias alive.

Bambuí and Rio de Janeiro, August 2008.

João Carlos Pinto Dias

Senior Researcher of Fundação Oswaldo, Member of the Minas Gerais Academy of Medicine and of the Editorial Board of Mem Inst Oswaldo Cruz

José Rodrigues Coura Senior Researcher of Fundação Oswaldo, Member of the National Academy of Medicine and former Editor of Mem Inst Oswaldo Cruz 